
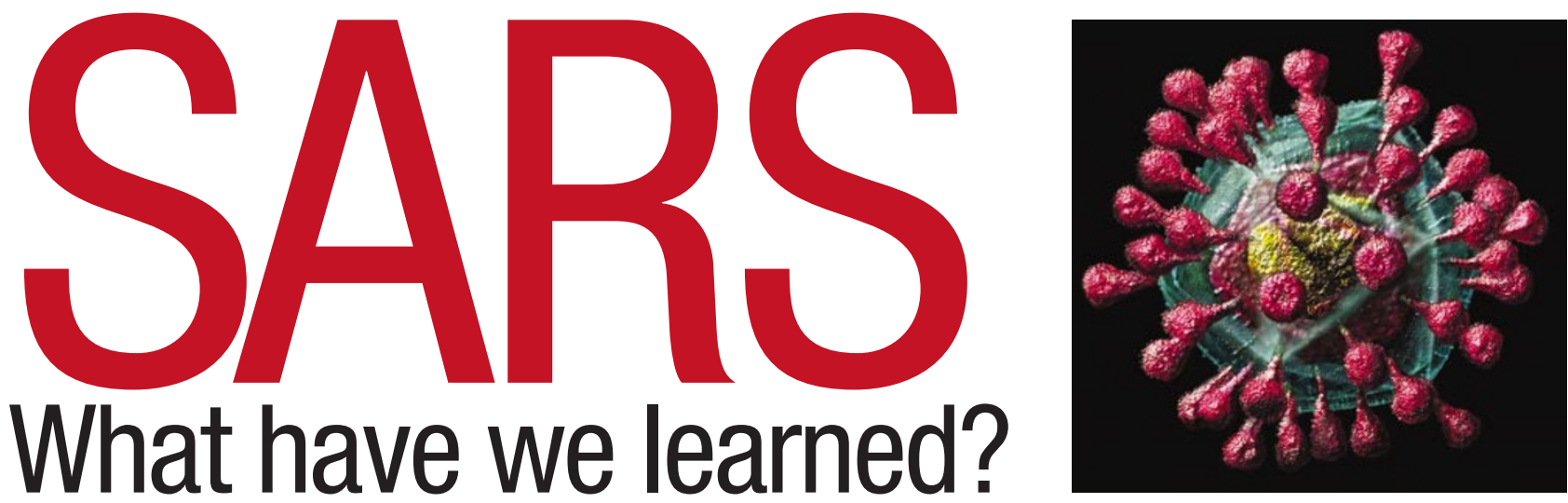

It's less than four

months since the World Health Organization issued global warnings about a mysterious and deadly form of pneumonia. Nature's reporters pose key questions about the outbreak, and assess our preparedness to deal with future viral threats.

\title{
Was the fuss overblown?
}

$\mathrm{T}$ o the friends and relatives of the 800 plus people slain by severe acute respiratory syndrome (SARS), this might seem like a callous question. But SARS barely registers a blip in the annual body count caused by infectious disease. Influenza is likely to kill up to half-a-million people in 2003, whereas the death tolls from malaria, tuberculosis and AIDS will each run to seven figures. So, when the outbreak is put into perspective, was the panic over SARS really warranted?

Given the economic damage suffered by those countries named by the World Health Organization (WHO) in its warnings against travel to the worst affected regions, some commentators have accused the WHO of overreacting - local officials in the Canadian city of Toronto, in particular, were livid about the agency's advice against travelling there. But the experts contacted by Nature are unanimous in rejecting the general idea that health authorities went over the top.

When reports of an unusual respiratory illness began to emerge from southern China

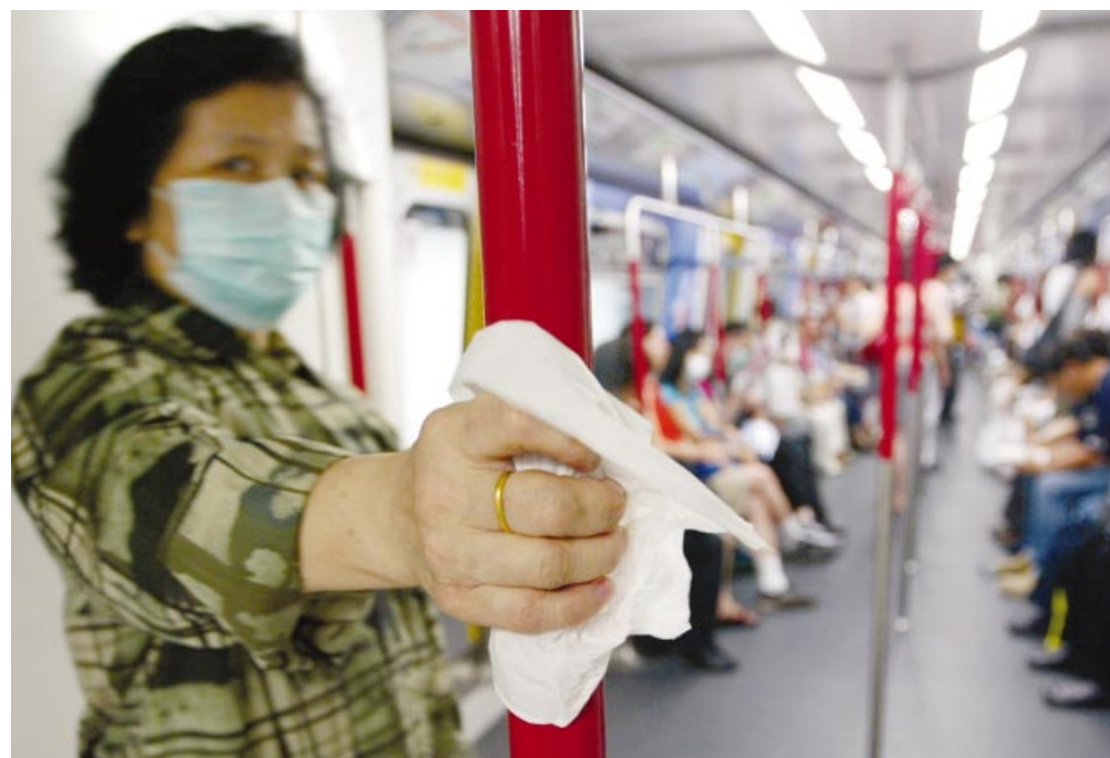

High alert: caused by a coronavirus (top), SARS left many in Hong Kong in the grip of fear.

late last year, no one knew what caused it. Was this a new super-virulent strain of flu? If so, would it be as deadly as the 1918 pandemic strain, which killed up to 40 million people? Even in mid-March, when outbreaks elsewhere in Asia caused the WHO to release the two global alerts that shot SARS onto the world's news agenda, the culprit remained unknown. Also unclear were the disease's death rate and infectiousness. Health officials could not be sure whether they were dealing with a troubling but ultimately limited threat, or a global mass killer.

Thankfully, it seems that SARS isn't sufficiently infectious to cause a re-run of the 1918 flu pandemic. Even so, the relatively low death count can probably be attributed in large part to the surveillance and patient isolation rapidly introduced in most of the countries that imported the disease. China has been widely criticized for the initially sluggish and secretive response that allowed SARS to take hold within its borders. But after the WHO issued its global alerts, only Taiwan — where officials failed to rapidly establish a central coordinating office for SARS - experienced an outbreak in which there was widespread transmission among people other than health workers caring for SARS victims.

Although experts agree that SARS warranted a vigorous reaction, questions remain about the way in which the threat was communicated to the public. The WHO's executive director for communicable diseases, David Heymann, acknowledges that problems were caused by the agency's second global alert, issued on Saturday 15 March when some ministries of health were closed, after evidence emerged that the disease was being spread internationally. As a result, the media were running with the story before national officials had been briefed about how to respond. To rectify this, the WHO's general assembly in May urged member states to designate officials who will be available around the clock to be informed about future urgent global alerts.

Another problem was that some national agencies, even the respected US Centers for Disease Control and Prevention (CDC) in Atlanta, Georgia, released information that inadvertently exaggerated the ease with which SARS spreads. For example, in a editorial in The New England Journal of Medicine ${ }^{1}$ 


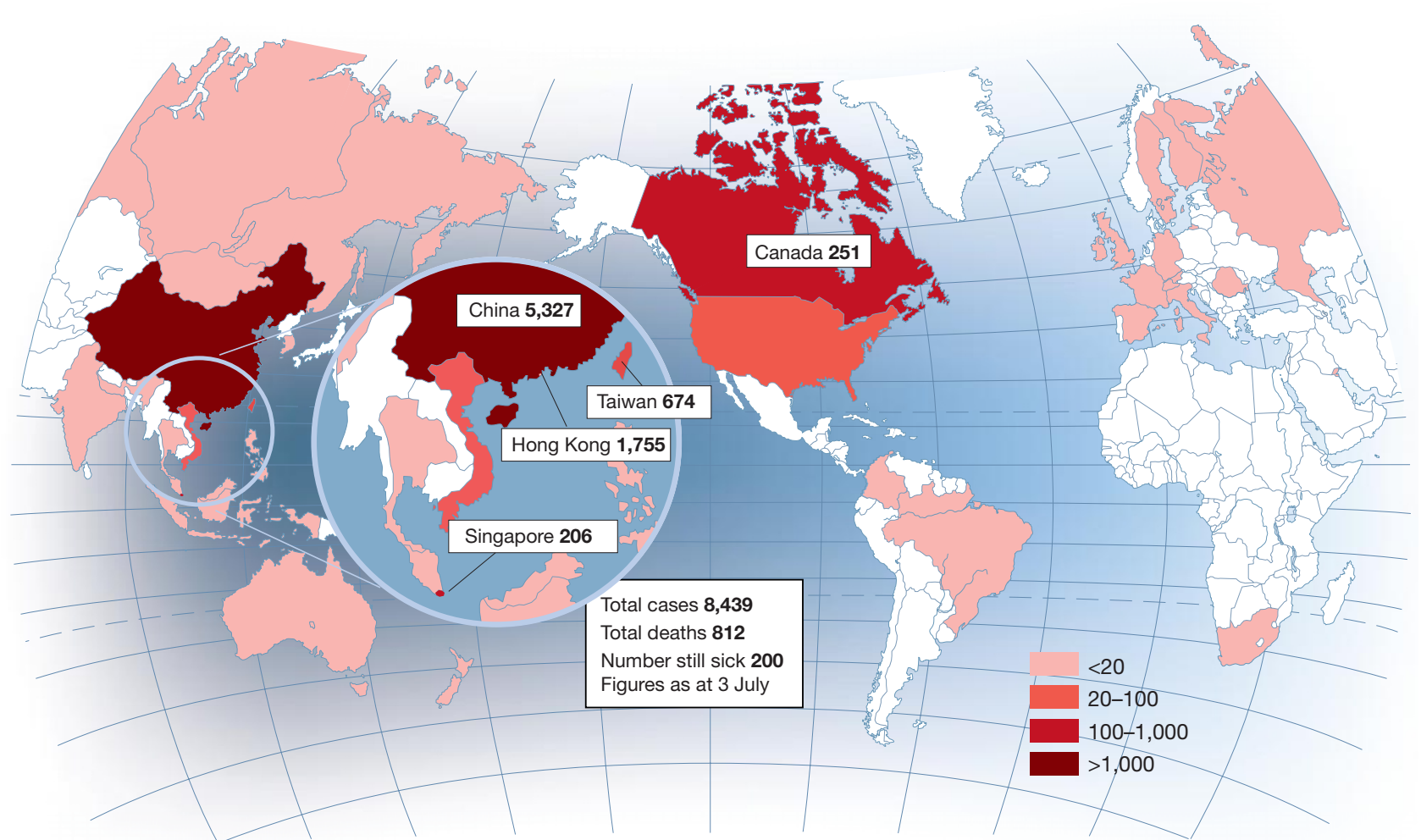

Pattern of an epidemic: the total number of SARS cases worldwide (above) was contained thanks to global alerts and patient quarantine; and the number of new cases (right) has now tailed off.

published online on 2 April, CDC director Julie Gerberding wrote: "Airborne transmission may have a role in some settings." No wonder that people in Hong Kong and elsewhere were scared into wearing surgical masks in the street, even though clinical reports suggested that SARS was being spread only by close personal contact.

But these were minor glitches. Experts agree that it is better to be accused of overreacting than of allowing the disease to run out of control. If a similar fuss had erupted in the early days of AIDS, suggests epidemiologist Megan Murray of the Harvard School of Public Health in Boston, maybe HIV would not now be killing three million people each year.

Helen Pearson

\section{Is the outbreak finally over?}

With luck, the answer is yes. At the outbreak's peak in early May, some 200 new cases were being reported every day. But as Nature went to press, no new cases had been reported since 15 June. "In some senses, we should breathe a sigh of relief," says Roy Anderson, whose team at Imperial College London has been at the forefront of efforts to characterize the spread of the disease.

For Anderson and other epidemiologists who have been crunching the numbers on SARS, the key parameter is known as $R_{0}$. A measure of a disease's infectiousness, $R_{0}$ corresponds to how many people, on average, are infected by each patient in the absence of any control measures.

Attempts at modelling the spread of SARS, published online on 23 May by teams led by Anderson and by Marc Lipsitch of the Harvard School of Public Health ${ }^{2,3}$, gave $R_{0}$ a value of between two and four. This was encouraging news, as it confirmed that efforts to isolate patients should bring the disease under control. Contrast this with flu, which boasts an $R_{0}$ of about 10 . For diseases this infectious, quarantining those who show symptoms is not enough to bring the average number of new infections caused by each case to below one - the level necessary for an epidemic to go into decline.

But we still know too little about SARS to predict how it will behave should it return. Key unknowns include how quickly a person becomes infectious after they are infected, and how long they remain able to spread the disease. Most importantly, we don't know exactly how the virus is transmitted, how many people harbour the SARS virus without showing symptoms, and whether these 'silent' cases can infect others.

The relatively sluggish transmission of SARS fits with the idea that it is spread by close contact, requiring its victims to breathe in droplets of virus-laden mucus. That explains why most transmission has been in confined settings, such as hospitals. But unusual foci of infection in Hong Kong show

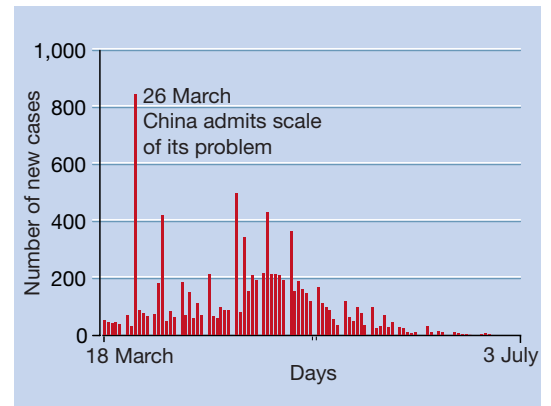

that this isn't the whole story. Most striking was the outbreak at the Amoy Gardens apartment block, where the brother of one resident seems to have infected 321 other people. Scientists tore the block apart, eventually implicating a faulty sewage system that allowed droplets contaminated with faeces to form in the block's bathrooms ${ }^{4}$. Transpose SARS to a developing country with poor sanitation, therefore, and the dynamics of its spread might be different.

If SARS does return at a later date, its epidemiology could be different. For reasons that aren't fully understood, respiratory infections spread more rapidly during the winter. Another crucial question is how long immunity to SARS persists. If this is as short as a few months, and SARS bounces back with the next Northern Hemisphere winter, even those previously exposed to the virus may be just as vulnerable as they were the first time around. "It's quite possible that we haven't seen SARS at its full force," warns Donald Burke, an international health 
expert at Johns Hopkins University in Baltimore, Maryland.

In the meantime, epidemiologists are trying to work out how many people are silently harbouring the SARS virus. If a sizeable number of symptomless cases can transmit the disease, outbreaks will continue to erupt. Investigating this question will require better diagnostic tests - to detect both antibodies to the SARS virus, and the virus's genetic material. Ideally, these won't require laborious analysis of blood samples. "We need a saliva test," says Anderson.

The greatest danger is if health officials let down their guard now that SARS seems to have waned. A second outbreak in Toronto in late May, weeks after the last new case was reported in the city, provided a warning. In this instance, a patient was discharged from hospital with pneumonia - common among elderly people who have undergone surgery - that turned out to be SARS.

Tom Clarke

\section{Are we prepared for the next viral threat?}

SARS should be seen as a warning shot. If the virus had been more infectious, we could now be facing millions of deaths. And this nightmare vision doesn't require the emergence of an entirely novel disease: new strains of flu virus arise each year, and every few decades, one appears that wreaks global havoc. So, in the light of our experience with SARS, are we prepared? Scientifically, the answer is a qualified 'yes'. In terms of public health, it's a resounding 'no'.

The most encouraging thing about the response to SARS is the way in which virologists worked together to identify and understand the pathogen responsible. The four collaborating centres in the WHO's Global Influenza Surveillance Network - in Australia, Britain, Japan and the United States were soon teamed up with seven other leading virology laboratories to probe the mysteries of SARS. Within a few weeks of the WHO issuing its global health alerts, labs in this network had identified the culprit as a previously unidentified strain of coronavirus $^{5-7}$, and a prototype diagnostic test was made available ${ }^{7}$.

The network was all about sharing data, resources and time. Results were posted on a

\section{SARS facts}

Symptoms Initially fever, sometimes accompanied by headache; later a dry cough, trouble with breathing, nausea and diarrhoea.

- Incubation period 2-10 days

- Economic cost Nearly US\$100 billion,

mostly as a result of cancelled travel and decreased investment in southeast Asia, according to Bio Economic Research Associates of Cambridge, Massachusetts.
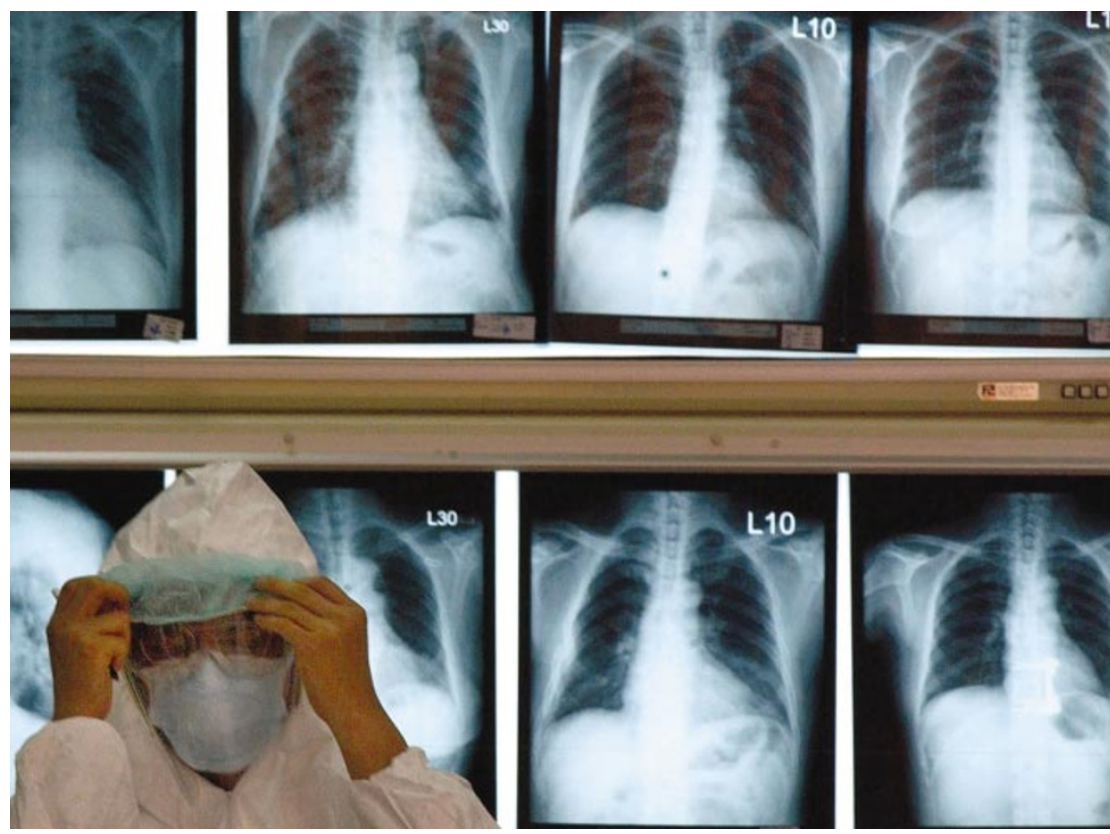

The dark lesions on these X-rays show the debris and fluid blocking the lungs of patients with SARS.

password-protected website as soon as they were gathered, and were discussed daily in teleconferences that sometimes stretched over three hours. Most helpful, say insiders, was the prompt reporting, from the word go, of blind alleys. "We had already run through the list of obvious possibilities when the network started, and so could tell the partners not to look for certain viruses," says network member John Tam of the Chinese University of Hong Kong.

Sharing of materials and reagents was also fundamental. The SARS agent was shown to be a coronavirus by amplifying portions of its genetic material using the polymerase chain reaction (PCR), and examining the resulting sequences. But this approach is only feasible if you have the appropriate PCR 'primers', corresponding to short genetic sequences from known virus families. Without the sharing of primers across the collaborating network, says William Bellini, SARS laboratory coordinator at the CDC, the virus would not have been identified so quickly.

WHO officials attribute the rapid scientific progress made by the SARS network in part to the experience of the influenza labs around which it was constructed. "We had a core of people, definitely not ivory-tower people, who were used to working in this way," says Klaus Stöhr, the WHO's influenza project leader, and its resident SARS expert. He is now building further networks to share clinical experience and data from SARS patients, and to link groups trying to identify animal reservoirs of the SARS virus.

Unfortunately, a speedy scientific reaction to an emerging viral threat doesn't guarantee that public-health officials will be able to mount an effective response. Faced with a more rapidly spreading disease, the consensus is that they would have been overwhelmed. And although health authorities might claim that it is unreasonable to expect them instantly to be able to tackle a disease that pops up out of the blue, most nations remain woefully unprepared to deal with a flu pandemic that could emerge at any time.

Through the WHO's efforts, emerging strains of flu virus are constantly monitored in the hope that vaccines can be produced that protect against those in general circulation. But if a pandemic strain does emerge, health officials will also need to deploy antiflu drugs on a massive scale. "We know that another flu pandemic will occur," says Albert Osterhaus, a virologist at Erasmus University in Rotterdam, the Netherlands, who participated in the SARS network. "But no country has yet started to stockpile antiviral drugs."

Alison Abbott

\section{How and who does SARS kill?}

No two cases of SARS are exactly the same. Depending on the age and fitness of the patient, the disease can run wildly different courses. Even the symptoms of fever and dry cough, initially included in the case definition for SARS, are no longer considered to be universal.

One pivotal point seems to occur at about the beginning of the third week after infection, when some patients, especially the young, improve. Others, however, progress to a more severe form of the disease - their lungs become clogged with debris and fluid, which show up as dark lesions in chest $\mathrm{X}$-rays. In about a fifth of all patients, this 
requires aggressive treatment such as mechanical ventilation. Even then, many of these people die.

Worldwide, the death rate from SARS seems to be about $10 \%$. But individual risk factors vary considerably. For people over 65 years of age, more than half of those infected will die. Just about any lung ailment complicates the disease, and conditions such as emphysema are more common in the elderly. Other concurrent infections may also be involved. Although it is now well established that the SARS virus can kill on its own ${ }^{8}$, other viruses that have been isolated from patients with SARS $^{9}$ could exacerbate the illness.

The ultimate cause of death also remains unclear. Does the virus kill directly by destroying cells in the lung, or does the immune system deliver a coup de grâce by fighting back too hard? By the time that most of the lung damage occurs, the amount of virus circulating in the blood has already peaked $^{10}$, suggesting the latter. And the pattern of damage is consistent with an overload of cytokines ${ }^{9}$ - biochemical messengers that rev up our immune responses. But for the time being, pathologists are recording an open verdict.

Jonathan Knight

\section{Where did the SARS virus come from?}

The SARS coronavirus is believed to have jumped over from an animal host to people in rural areas of Guangdong province in southern China. From November last year, it circulated there for several months while Chinese health authorities failed both to tackle its spread, and to provide adequate information to their counterparts in other countries about what was going on. But the path that the virus took to set up this initial hotbed of human infection - essential information for assessing the likelihood of a recurrence, even if the initial wave of SARS is over - remains a mystery.

Coronaviruses are named after their crown-like halo of protein spikes, which help them to latch on to their host cells. Those previously identified in people cause nothing nastier than common colds, but some of the coronaviruses that afflict livestock and pets cause more serious conditions.

Analysis of the complete genome sequence of the SARS virus, published in May $^{11}$, suggests that it is not closely related to any of the three previously identified coronavirus subfamilies, nor does it seem to have arisen through a chance genetic recombination between known coronaviruses ${ }^{12}$. "Its unique sequence suggests that it has evolved independently from the other members of the family, in some animal host, for a long time," says Malik Peiris, a virologist at the University of Hong Kong.

Ongoing research by Peiris and his col-

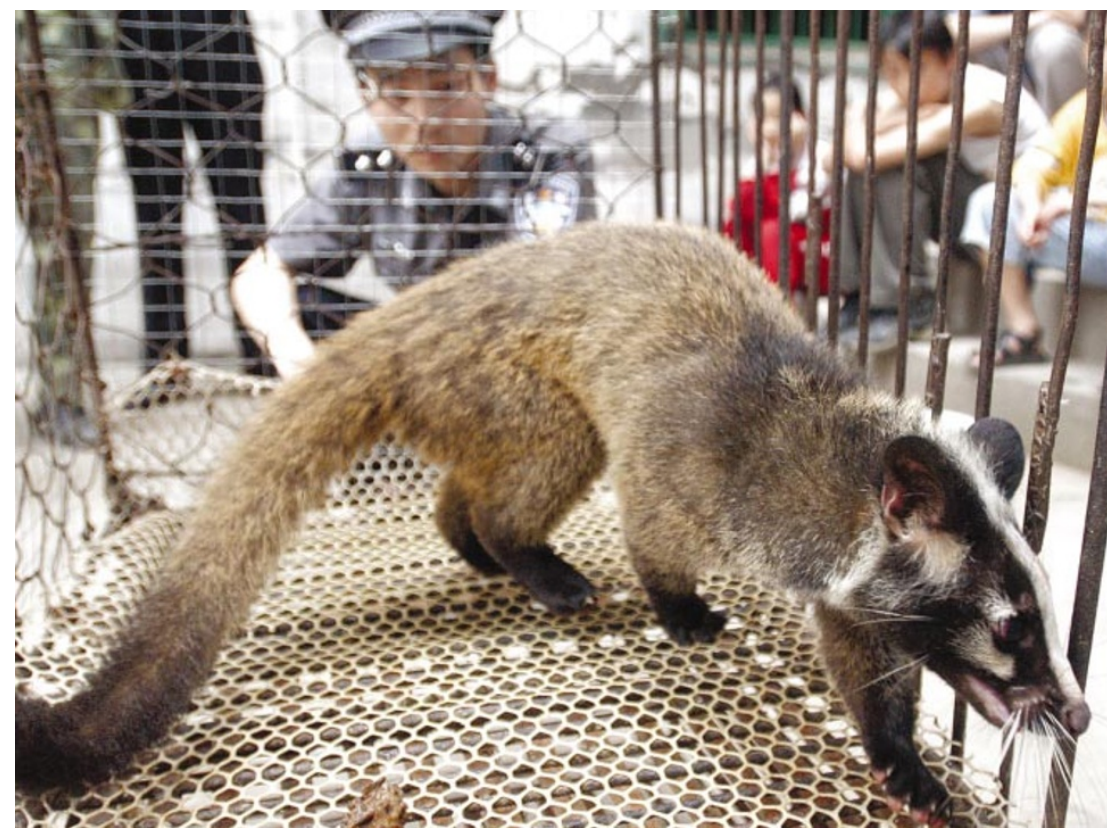

Wild animals, such as the palm civet, sold in Chinese markets, might have passed SARS to humans.

leagues may shed light on the origins of the virus. The Hong Kong team is looking at genomic sequences of coronaviruses sampled from masked palm civets (Paguma larvata) and other animals sold in the markets of southern China. Comparison of the sequences of the viruses found in different animals should make it possible to trace the evolution of the SARS virus and determine which animal passed the disease to humans. Yi Guan, another member of the Hong Kong team, says that related viruses have so far been found in about half-a-dozen species which he declines to name until the work has been published.

Knowledge of the chain of animals involved in passing the SARS virus to humans would help in the design of preventive measures. For example, when the previously unidentified Nipah virus began causing fatal encephalitis in livestock and people in Malaysia in 1998, about one million pigs were slaughtered. Later the

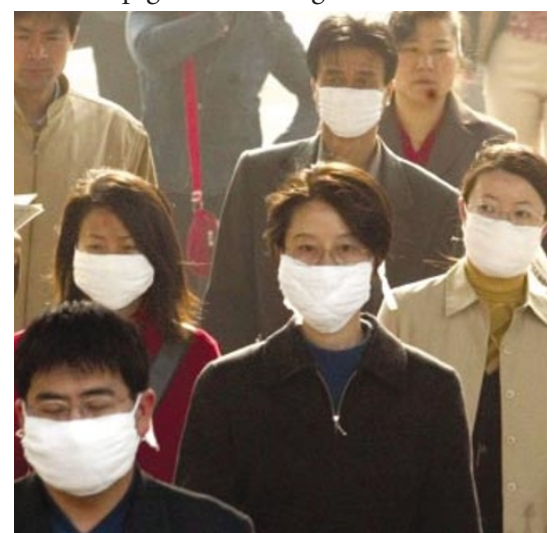

Protect and survive: residents of Beijing make their way to work at the height of the SARS crisis. virus was found to reside in fruit bats ${ }^{13}$, so farmers could take measures to isolate their livestock from this natural reservoir. "Once you find the source, you can find out how to manage it better," says John Mackenzie, a virologist at the University of Queensland in Brisbane, Australia.

It will probably be some time before we pin down the natural reservoir for SARS. Recent investigations by researchers at the China Agricultural University in Beijing, for instance, have failed to find SARS-like coronaviruses in 732 animals from 54 wild and 11 domestic species in southern China, including palm civets. As with efforts to investigate the epidemiology of SARS in people, progress may depend on the development of improved diagnostic tests. But potentially, Guan warns, revealing the origins of SARS could require decades of painstaking fieldwork.

David Cyranoski

\section{Why China?}

SARS is not the first viral disease to burst out of China or Hong Kong. The southern Chinese region was the source of influenza pandemics in 1957 and 1968, and scares about the transmission to people of novel strains of avian flu in 1997 and 2001. Why does this region keep throwing up viruses that have the potential to threaten the lives of people around the world?

Southern China's status as the world's primary breeding ground for new strains of flu is explained by the fact that its people, pigs and domestic fowl, which all harbour influenza viruses, live cheek-byjowl, increasing the likelihood that two strains will recombine genetically to produce a deadly new variant. "The animals walk in 


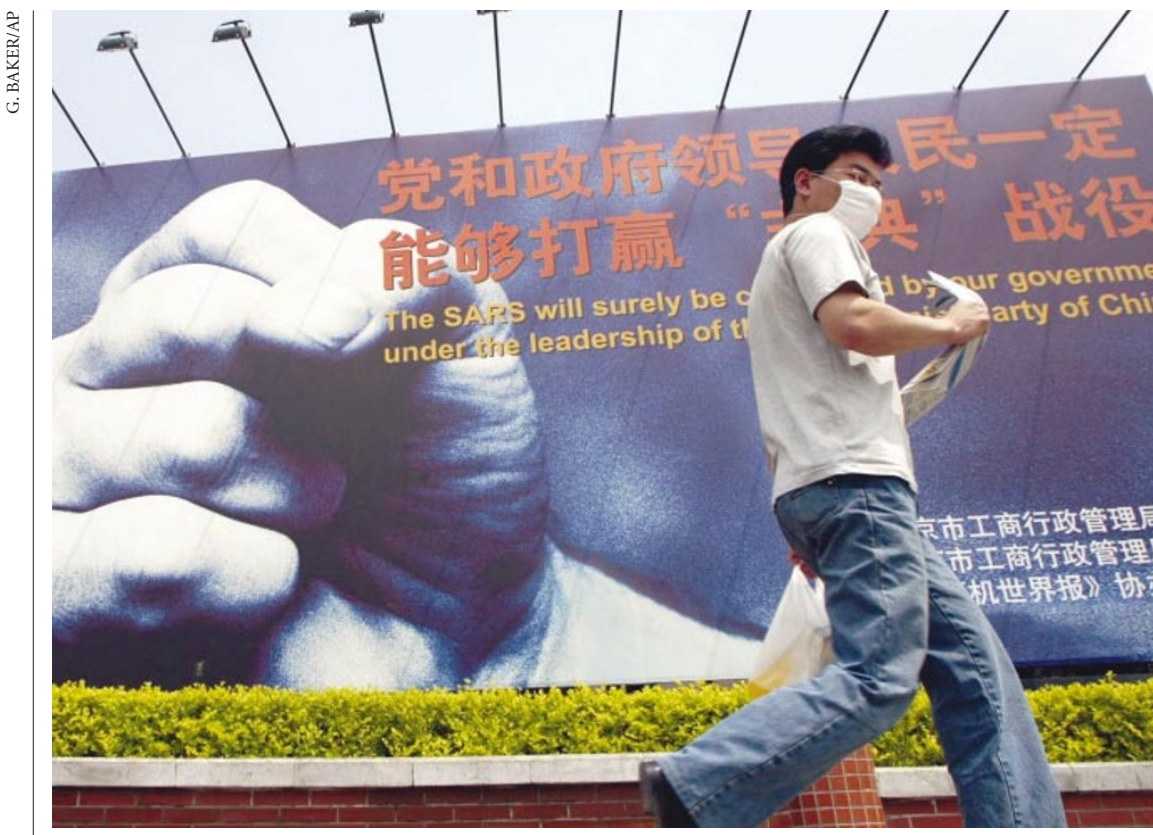

Despite the propaganda, China has been criticized for its initially slow and secretive response to SARS.

and out of their houses," says Kenneth Shortridge, who led the University of Hong Kong's efforts to monitor avian viruses in southern China until his retirement last year. Preliminary evidence suggests that SARS followed a different model, apparently crossing over to people from wild animals, rather than livestock. But this, too, is not terribly surprising, given that the southern Chinese make widespread use of wild species for food and traditional medicine - practices that Chinese health officials are now trying to discourage.

Another dietary issue - specific nutritional deficiency — has also been tentatively linked to the emergence of new viral strains in rural China. For instance, in many parts of the country, the diet is lacking in the trace element selenium. A team led by Melinda Beck of the University of North Carolina at Chapel Hill found that when the coxsackievirus B3 infects mice deficient in selenium, it mutates at a much higher rate and can become more virulent ${ }^{14}$. Beck suspects that this phenomenon may explain the high incidence of Keshan disease, a weakening of the heart muscle, in some Chinese populations ${ }^{15}$. She has also observed increased mutation rates in flu viruses infecting selenium-deficient mice ${ }^{16}$. "The fact that China has widespread selenium-deficient areas may play a role in the emergence of new viral strains,"Beck claims.

Other scientists regard Beck's findings as speculative, and doubt whether they offer a general explanation for the emergence of viral diseases in China. When you have the world's largest population interacting closely with livestock and wild animals, say experts, it's hardly surprising that China seems to be the origin of so many viral outbreaks. "It's a matter of exposure probability," suggests Mei-Shang Ho, an epidemiologist with Academia Sinica's Institute of Biomedical Sciences in Taipei, Taiwan.

David Cyranoski

\section{Is the SARS virus mutating?}

Viruses such as HIV and those that cause influenza have often been described as 'wily' because they mutate rapidly, a trait that helps them to evade drugs or the human immune system. But so far, the SARS virus seems remarkably invariant: the genome sequences of 14 isolates from patients in Singapore, Toronto, China and Hong Kong have not revealed any changes of real consequence ${ }^{17}$.

This isn't because the SARS virus fails to mutate, but rather that the mutations thrown up so far haven't proved to be particularly beneficial to it. As the virus has so far encountered little resistance from its new human hosts, there has been little selective pressure to cause new mutants to be retained.

Coronaviruses are quite sloppy when it comes to replicating their genetic material, making one error for every 10,000 nucleotides they copy - roughly the same error rate as HIV. But coronaviruses have a trait that allows them to weed out mutations as they occur. Rather than relying on a single template genome, the enzyme responsible for copying the viruses' genetic material sometimes jumps around between multiple copies of the viral genome present in an infected cell. So each new genome is actually copied from several templates, reducing the chance that any given mutation will become entrenched in the viral population.
But if one of these jumps is imprecise, a whole chunk of genome can get skipped, resulting in the deletion of part of an important gene. The consequences can be dramatic, particularly if the change affects the protein spikes that bind to the surface of the viruses' cellular victims. For example, in 1984 a new respiratory ailment appeared on European pig farms. It turned out to be a deletion mutant of a coronavirus that previously had infected piglets' stomachs ${ }^{18}$. The altered spike protein had changed the type of cells the virus could enter. Although the new disease was not generally lethal, it has since spread worldwide and complicated diagnosis of the gut disease.

A genetic deletion may also have helped the SARS virus to make the transition from its animal reservoir to humans. But, if so, it is a different type of change - the spike protein remains intact. Instead, compared with the viral strains found in animals on sale in southern Chinese markets, the SARS virus lacks 29 nucleotides in the gene for a protein of unknown function, which is attached to the inside of the virus's protective coat.

Should SARS return to haunt us, it will probably not remain as stable as it has been so far, particularly if it is attacked with antiviral drugs. Our immune systems could force changes, too. "Once enough people develop immunity, mutations will be favoured, just as you see with flu viruses," predicts Michael Lai, a molecular virologist at the University of Southern California in Los Angeles.

Jonathan Knight

\section{Are drugs for SARS on the horizon?}

From the moment the viral culprit behind SARS was unmasked, drug-discovery researchers leapt into action. So far, the main approach has been one of brute force: screening hundreds of thousands of compounds for their ability to attack lab cultures of the virus.

The US National Institute of Allergy and Infectious Diseases in Bethesda, Maryland, is coordinating a massive random screen of both licensed drugs and those still under development. This work has been contracted to the US Army Medical Research Institute of Infectious Diseases at Fort Detrick, also in Maryland, where more than 300,000 compounds - many of them supplied by pharmaceutical companies - have so far been tested on viral cultures grown in monkey kidney cell lines. "We've had lots of hits, and some are looking better than others," says Fort Detrick virologist Robert Baker.

A similar, but smaller initiative, based at the University of Frankfurt in Germany, has shown that a compound called glycyrrhizin, derived from liquorice roots, can rid monkey kidney cells of the SARS virus ${ }^{19}$. In work that has yet to be published, the Frankfurt team has 
confirmed the effectiveness of glycyrrhizin in a human cell line. Although relatively nontoxic and already licensed for use in conditions including hepatitis $\mathrm{C}$, glycyrrhizin only works at very high doses. So the Frankfurt researchers, led by Prakash Chandra, are collaborating with medicinal chemists at the Russian Academy of Sciences' Institute of Organic Chemistry in Moscow, who have synthesized a series of related compounds ${ }^{20}$. They hope that one of these will prove particularly effective against the SARS virus.

Other researchers are trying a more directed approach. Erik De Clercq of the Catholic University of Leuven in Belgium, for instance, is screening selected compounds from his large library of antiviral chemicals, many of which interfere with viral replication. "I believe that rational screening based on putative targets is likely to be more efficient than random screens," he says.

Rolf Hilgenfeld, a structural biologist at the University of Lübeck in Germany, meanwhile, has solved the structure of a key SARS enzyme called proteinase, which turns viral proteins into the active forms required for viral replication ${ }^{21}$. Using a computer model of this structure, his team has also begun to predict which drugs might inhibit the enzyme's activity. Hilgenfeld is now collaborating with a Chinese group led by Jiang HuaLiang of the Shanghai Institute of Materia Medica, which has the supercomputing power to expand upon this work.

But the difficult part will be moving into animal experiments and eventual human trials. So far, there is only one validated animal model for SARS, the cynomolgus macaque (Macaca fascicularis) ${ }^{8}$, which isn't ideally suited for large-scale investigations of candidate drugs. A good small-animal model is urgently needed, say researchers. Alison Abbott

\section{What about a vaccine?}

If SARS stages a comeback, the best tool for blunting its threat will be an effective vaccine. And the good news is that vaccines already exist for animal coronaviruses. "We can immediately apply this expertise to SARS," says virologist Peter Rottier of Utrecht University in the Netherlands, who is developing a vaccine against a coronavirus that kills cats. Another encouraging sign is that the condition of SARS patients seems to improve if they are given serum from previously infected people, which indicates that human antibodies can neutralize the virus.

Perhaps the easiest approach is to stimulate immunity using a killed SARS virus. "It's the first thing we'll try," says Rino Rappuoli of vaccine manufacturer Chiron in Siena, Italy. But relying on killed viruses is not ideal — in part because ensuring that all viruses in a vaccine are dead and yet retain the ability to stimulate the immune system is tricky.

The next option is a weakened SARS virus

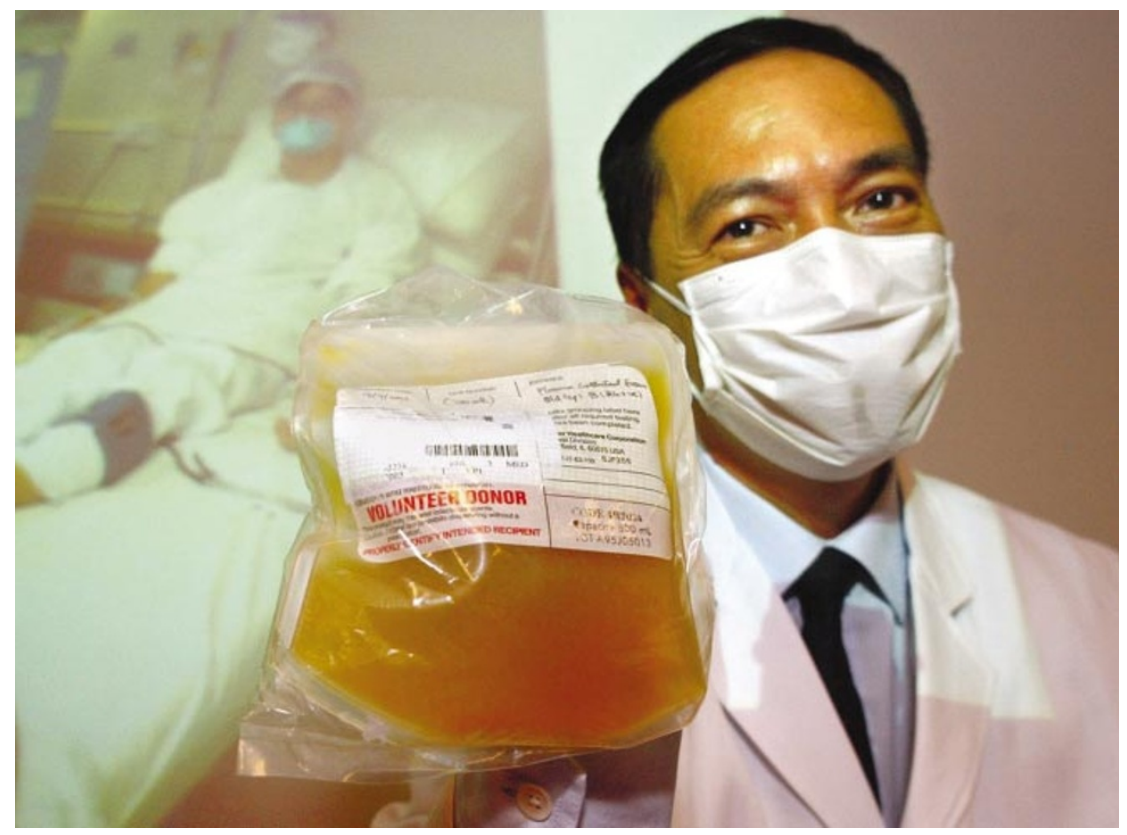

Fighting back: serum from previously infected people seems to help treat other SARS patients.

that can survive in humans long enough to challenge the immune system, but which doesn't cause disease. Such vaccines are normally made by culturing viruses in animal cell lines for generation after generation, selecting each time for the least potent offspring. They have the advantage that they can be made to infect cells in the respiratory tract - which may prove crucial to stopping SARS in its tracks. But safety remains an issue, as a weakened strain might mutate to become a lethal virus in its own right.

The best way around this, and the approach that Rottier has used to make a prototype cat coronavirus vaccine, is precisely targeted genetic modifications. Genes not needed for the virus's survival but required for it to cause disease are removed. All of the known coronaviruses, including the SARS virus, seem to have these genes in common, and knocking them out wholesale would make it almost impossible for the SARS virus to mutate back to a dangerous form. But there is still the chance that it could recombine with other coronaviruses to recover its lethal genetic machinery.

Other approaches avoid any possibility of a vaccine causing SARS. For instance, harmless viruses could be engineered to contain genetic sequences from the SARS virus. Such vaccines could again be made to infect cells in the respiratory tract, and the approach has been used successfully in animals - for instance in a prototype vaccine against a coronavirus that causes bronchitis in chickens ${ }^{22}$. A simpler and even safer alternative would be vaccines based on viral proteins that stimulate the immune system, but this approach has had only limited success against animal coronaviruses.

What works in animal diseases may not provide a perfect guide to developing a SARS vaccine, however. Experience has shown that individual coronaviruses can interact with their hosts in quite distinct ways. "The trick is finding a vaccine that pushes all the right immunological buttons," says Dave Cavanagh at the Institute for Animal Health at Compton in Berkshire, UK. Finding a candidate that achieves this against the SARS virus will require extensive studies in animals.

If all goes well, a SARS vaccine could reach the market in as little as four years, say experts. But there's a lot that could go wrong at any stage. So for the foreseeable future, health officials had better plan on tackling the disease without this key defensive weapon. Tom Clarke

1. Gerberding, J. L. N. Engl. J. Med. 348, 2030-2031 (2003).

2. Riley, S. et al. Science 300, 1961-1966 (2003).

3. Lipsitch, M. et al. Science 300, 1966-1970 (2003).

4. http://www.info.gov.hk/info/ap/pdf/amoy_e.pdf

5. Peiris, J. S. M. et al. Lancet 361, 1319-1325 (2003)

6. Ksiazek, T. G. N. Engl. J. Med. 348, 1953-1966 (2003).

7. Drosten, C. N. Engl. J. Med. 348, 1967-1976 (2003).

8. Fouchier, R. A. M. et al. Nature 423,240 (2003).

9. Nicholls, J. M. et al. Lancet 361, 1773-1778 (2003)

10. Peiris, J. S. et al. Lancet 361, 1767-1772 (2003).

11. Marra, M. A. et al. Science 300, 1399-1404 (2003).

12. Rota, P. A. et al. Science 300, 1394-1399 (2003)

13. Yob, J. M. et al. Emerg. Infect. Dis. 7, 439-441 (2001).

14. Beck, M. A., Shi, Q., Morris, V. C. \& Levander, O. A. Nature Med. 1, 433-436 (1995)

15. Levander, O. A. \& Beck, M. A. Biol. Trace Elem. Res. 56, 5-21 (1997). 16. Nelson, H. K. et al. FASEB J. 15, 1846-1848 (2001).

17. Ruan, Y. et al. Lancet 361, 1779-1785 (2003).

18. Pensaert, M., Callebaut, P. \& Vergote, J. Vet. Q. 8, 257-261 (1986). 19. Cinatl, J. et al. Lancet 361, 2045-2046 (2003).

20. Baltina, L. A. Curr. Med. Chem. 10, 155-171 (2003).

21. Anand, K., Ziebuhr, J., Wadhwani, P., Mesters, J. R. \& Hilgenfeld, R. Science 300, 1763-1767 (2003).

22. Johnson, M. A., Pooley, C., Ignjatovic, J. \& Tyack, S. G. Vaccine 21, 2730-2736 (2003).

\section{www.who.int/csr/sars/en/index.html \\ www.cdc.gov/ncidod/sars \\ www.sars.gc.ca}

1 www.info.gov.hk/info/sars/eindex.htm

Nature's SARS focus

www.nature.com/nature/focus/sars 